\title{
PBT borderline chemicals under REACH
}

\author{
Christiane Zarfl ${ }^{1,2^{*}}$ and Michael Matthies ${ }^{1}$
}

\begin{abstract}
Background: The European chemicals legislation REACH (Registration, Evaluation, Authorization and Restriction of Chemicals) defines criteria to identify substances of very high concern (SVHC). Within these, the property combinations 'persistent, bioaccumulative and toxic' (PBT) and 'very persistent and very bioaccumulative' (vPvB) are of specific priority. In Annex XIII, the determination of SVHC by 'weight-of-evidence' is also underlined, e.g. elevated pollutant concentrations in biota 'compared to levels in their surrounding environment', which may result from long-range transport potential (LRTP). Nevertheless, LRTP is not included explicitly, although substances may represent an environmental hazard to the intrinsic value of sensitive remote regions as highlighted in the Guidance for the implementation of REACH. Here, it is also recommended to include 'borderline cases', i.e. substances where one or more of the $\mathrm{P}, \mathrm{B}$ and $\mathrm{T}$ criteria are not met but an equivalent concern is given by other information, in particular LRTP.
\end{abstract}

Results: We define substances as potential borderline cases, which fail one of the criteria ( $\mathrm{VP}$ or $\mathrm{VB}, \mathrm{P}$ or $\mathrm{B}$ or $\mathrm{T}$ ) that have to be evaluated to identify SVHC by less than $10 \%$ and are, at the same time, identified to show high LRTP, and apply this definition to prioritize potential SVHC out of the list of 5,306 compounds registered in 2012 under REACH. Eight compounds can be identified as VPvB and less than 2\% as PBT compounds out of 1,022 organic, non-ionic substances. In addition, 13 borderline chemicals are contained in the list, which are characterized by LRTP.

Conclusions: Three compounds fail one of the VPVB/PBT criteria by less than 10\% only and show LRTP which strongly indicates that they should be considered as SVHC. Sensitivity analysis shows a rather stable classification around the arbitrarily fixed $10 \%$ value. It is concluded that several LRTP screening methods should be applied to reduce the uncertainty in LRTP determination.

Keywords: Long-range transport potential, SVHC, Prioritization, Implementation, Chemical assessment

\section{Background}

One of the major human impacts on the environment is the vast emission of chemical substances during production processes, by accident or intentionally, e.g. applying pesticides to protect agricultural plants. In order to reduce and avoid adverse effects on organisms and human health, legal systems take regulations for chemicals into account which might pose an inherent hazard to their environment. The European chemicals regulation REACH (Registration, Evaluation, Authorization and Restriction of Chemicals) aims to harmonize the chemicals legislations of the member states of the European Union and entered into force on 1 June 2007 [1]. Companies

\footnotetext{
* Correspondence: zarfl@igb-berlin.de

1 Institute of Environmental Systems Research, University of Osnabrück, Barbarastr. 12, Osnabrück 49076, Germany

${ }^{2}$ Leibniz-Institute of Freshwater Ecology and Inland Fisheries,

Forschungsverbund Berlin e.V, Müggelseedamm 310, Berlin 12587, Germany
}

which import or produce chemicals by 1 tonne or more per year have to register these compounds at the European Chemicals Agency (ECHA) in Helsinki. Furthermore, for substances of very high concern (SVHC) and above a tonnage level of 10 tonnes per year, a Chemical Safety Report has to be provided including exposure scenarios. It is therefore of high importance to identify those SVHC. But how is a SVHC defined? REACH specifies six cases in Articles 57 (a) to (f):

(a) The substance is carcinogenic.

(b) The substance is mutagenic.

(c) The substance is toxic to reproduction.

(d)The substance is persistent, bioaccumulative and toxic (PBT) according to the criteria given in Annex XIII of the REACH regulation.

\section{实}

(c) 2013 Zarfl and Matthies; licensee Springer. This is an Open Access article distributed under the terms of the Creative Commons Attribution License (http://creativecommons.org/licenses/by/2.0), which permits unrestricted use, distribution, and reproduction in any medium, provided the original work is properly cited. 
(e) The substance is very persistent and very bioaccumulative (vPvB) according to the criteria given in Annex XIII of the REACH regulation.

(f) The substance indicates to raise an equivalent concern to the cases above, e.g. having endocrinedisrupting properties, and thus having serious effects on humans and the environment. This has to be elucidated on a case-by-case study.

Furthermore, in Annex XIII, the following threshold values for $\mathrm{vP}, \mathrm{P}, \mathrm{vB}$ and $\mathrm{B}$ are defined for the identification of vPvB and PBT substances (cases (d) and (e)):

- vP: half-life of degradation in fresh water $>60$ days or in sediment $>180$ days or in soil $>180$ days

- P: half-life of degradation in fresh water $>40$ days or in sediment $>120$ days or in soil $>120$ days

- vB: bioconcentration factor $(\mathrm{BCF})>5,000 \mathrm{~L} \mathrm{~kg}^{-1}$

- B: $\mathrm{BCF}>2,000 \mathrm{~L} \mathrm{~kg}^{-1}$

According to Article 58, priority to including a substance on the list of SVHC in Annex XIV of REACH should be given to substances with PBT or vPvB properties, with wide dispersive use, or with high production volumes. Currently, there are 84 listings for SVHC candidates, thereof one substance is vPvB (musk xylene, CAS 81-15-2), three are PBT (bis(tributyltin)oxide, CAS 56-35-9; anthracene, CAS 120-12-7; hexabromocyclododecane (HBCD; $\alpha-, \beta$ - and $\gamma$-HBCD), CAS 25637-99-4), and one is both vPvB (57 e) and PBT $(57 \mathrm{~d})$ (short-chain chlorinated paraffins, CAS 85535-84-8).

Within Annex XIII of the REACH legislation, the identification of SVHC may also be justified on 'weightof-evidence' information, i.e. results from monitoring in the field, from suitable laboratory experiments, or on elevated pollutant concentrations in organisms compared to concentrations in their environment, especially in endemic or endangered species. This goes along with the recommendations of ECHA who points out in Chapter R.11 PBT Assessment of the Guidance on information requirements and chemical safety assessment that remote areas and their 'intrinsic value of pristine environments' (p. 7) should be protected from adverse effects of chemical substances [2]. In addition, 'borderline chemicals' which fail at least one of the persistence $(\mathrm{P})$, bioaccumulation (B) and toxicity (T) criteria but show an equivalent level of concern, e.g. by widespread distribution and long-range transport potential (LRTP), should be considered as SVHC within a PBT assessment. Nevertheless, the LRTP of an organic compound is not yet considered under REACH, although LRTP is also defined as a property of concern according to the Stockholm Convention on Persistent Organic Pollutants (POPs) [3] in addition to persistence, bioaccumulation and adverse effects.
Substances with LRTP cross international boundaries and may be transported via air, water [4] or with migrating animals to particularly sensitive ecosystems like the Arctic. This is of special interest when one substance fails or misses PBT or vPvB criteria slightly. Especially in these borderline cases, LRTP can be a significant property to indicate very high concern and support a prioritization of chemicals. Currently, the publicly available REACH database of end 2012 contains 5,306 publishable compounds registered in the European Union and can be downloaded from the official homepage of the European Chemicals Agency [5]. 'Publishable' substances include all of the 5,705 registered compounds except those where either the IUPAC name is claimed confidential according to REACH Article 119(2) (f) or (g) or where there has been no dossier disseminated. For the remaining 5,306 substances, at least one registration document has been processed and been published (in a filtered version) on the Dissemination Portal [5].

Finally, based on the suggestions within the guidance document [2], our aim is to define criteria for borderline chemicals and to support the prioritization of SVHC within the substances registered in the publicly available REACH database. A screening method will be applied to identify substances, which either fulfil the $\mathrm{PBT} / \mathrm{vPvB}$ criteria or, more importantly, which slightly fail these criteria but should also be considered as borderline cases for SVHC since their LRTP indicates a higher potential for adverse effects on the environment and human health. Prioritized substances will be investigated by a sensitivity analysis and an additional literature research to evaluate the assumptions on which the screening steps are based. This leads to a refined and reduced list of compounds whose properties strongly indicate very high concern and which should be investigated in more detail.

\section{Results and discussion}

\section{Screening for non-ionic compounds}

The publicly available REACH database contains 1,525 (28.7\%) organic compounds out of the total number of 5,306 publishable substances. Based on calculations with the online calculator SPARC v4.5 [6], 1,022 substances could be identified to be non-ionic to at least $95 \%$ within the environmentally relevant $\mathrm{pH}$ range of 4 to 10 . These chemicals remain for estimations with EPISuite v4.10 [6] to determine substance specific properties.

\section{Screening for persistence and bioaccumulation potential}

Besides basic properties, like molecular mass and partition coefficients, calculations with EPISuite v4.10 also resulted in estimates for half-lives in the different environmental compartments (water, sediment and soil) and for the BCF. Comparison of the values with respective 
criteria defined in the REACH regulation for persistence (P) and bioaccumulation potential (B) leads to a first classification of all substances according to $\mathrm{vP}, \mathrm{P}, \mathrm{vB}$ and B. Thus, the 1,022 substances can be classified into 8 substances $(0.8 \%)$ which are $\mathrm{vPvB}$ (sub-category (1)) and thus SVHC, and 1,014 compounds which are not vPvB (Figure 1). These comprise the following (' $\neg$ ' means 'not'):

- $15 \mathrm{vPB}$ (sub-category (2))

- $365 \mathrm{vP} \neg \mathrm{B}$ (sub-category (3))

- 2 PvB (sub-category (4))

- 3 PB (sub-category (5))

- 525 P $\neg$ B (sub-category (6))

- $0 \neg \mathrm{PvB}$ (sub-category (7))

- $2 \neg \mathrm{PB}$ (sub-category (8))

- $102 \neg \mathrm{P} \neg \mathrm{B}$ (sub-category (9))

In Figure 1, it is also indicated by a dashed line how many substances fail the criterion for $\mathrm{vP}, \mathrm{P}, \mathrm{vB}$ or $\mathrm{B}$ by not more than $10 \%$, e.g. 5 of the 104 substances which are $\neg \mathrm{P}$ fail the $\mathrm{P}$ criterion by less than $10 \%$, but all substances which are $\mathrm{P}$ fail the $\mathrm{vP}$ criterion by more than $10 \%$. This can be observed in a similar way for the bioaccumulation potential: 4 of the 992 substances which are $\neg \mathrm{B}(365 \mathrm{vP} \neg \mathrm{B}+525 \mathrm{P} \neg \mathrm{B}+102 \neg \mathrm{P} \neg \mathrm{B})$ fail the $\mathrm{B}$ criterion by less than $10 \%$, and 2 of the 20 compounds which are $\mathrm{B}(15 \mathrm{vPB}+3 \mathrm{~PB}+2 \neg \mathrm{PB})$ fail the vB criterion by less than $10 \%$.

These numbers would change if methods other than those implemented in EPISuite v4.10 for the estimation of half-lives and bioaccumulation were used to determine borderline chemicals. For instance, most chemicals are flagged as vP and P because of their half-life in sediment, which is due to the rather high extrapolation factor from their half-life in water calculated using BIOWIN3. Nevertheless, the structure of the procedure itself remains the same. Results for applying the bioaccumulation factor (BAF), which considers dietary uptake and biotransformation [7], instead of BCF to the B criteria defined under REACH can be found in the SI.

Since we are looking for borderline chemicals within the REACH database which are, in the first case, not SVHC, all vPvB substances can already be excluded from further investigations on toxicity. In addition, borderline chemicals fail one of the criteria ( $\mathrm{vP}$ or $\mathrm{vB}, \mathrm{P}$ or $\mathrm{B}$ or $\mathrm{T}$ ) that have to be evaluated to identify SVHCs and show LRTP according to at least one of the LRTP screening methods. Since for use in application, information on toxicity is the hardest to obtain and may vary significantly across different organisms and environmental conditions, the next screening step focusses on LRTP, although sub-categories (2) (vPB), (4) (PvB) and (5) (PB)

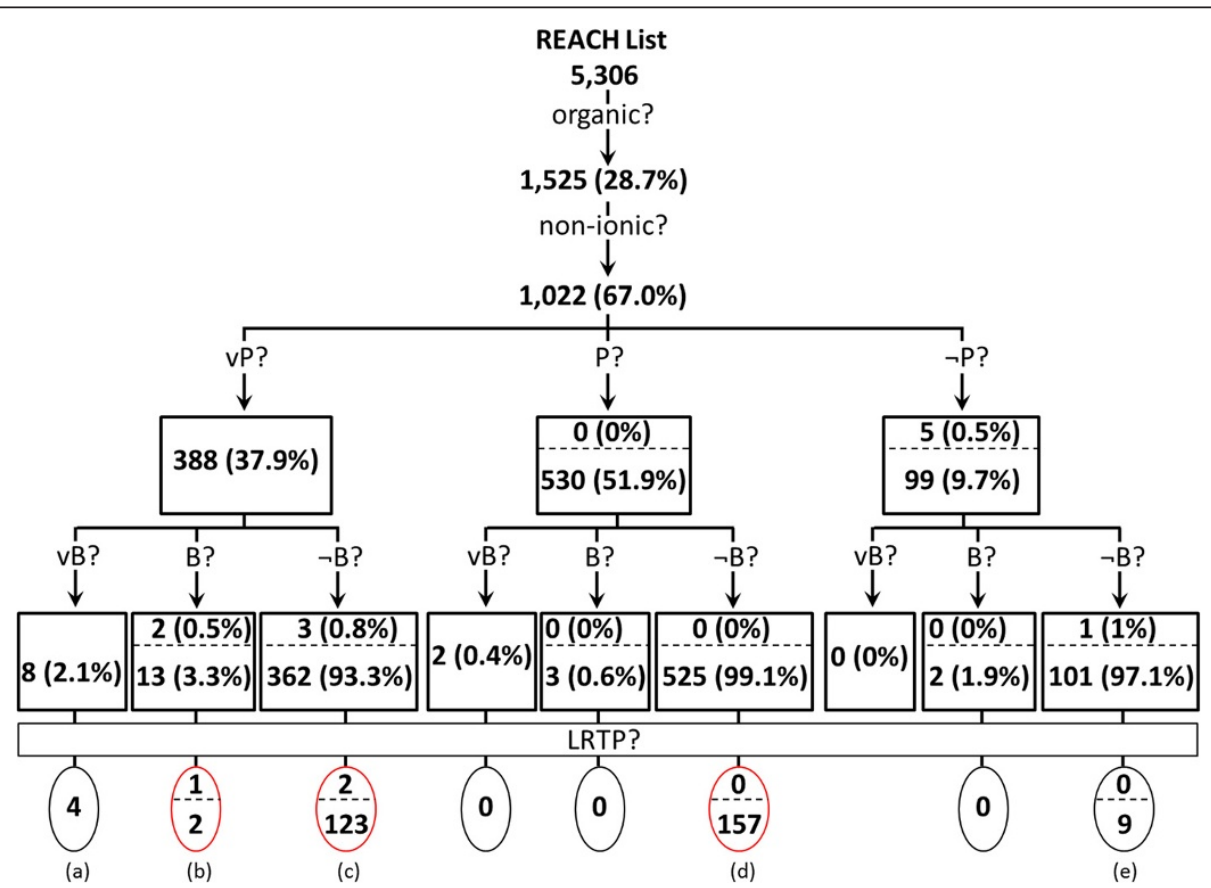

Figure 1 Flow chart illustrating the screening steps and resulting substance numbers for the publicly available REACH database. Classification of organic, non-ionic substances according to their persistence ( $V P$ - very persistent, $P$ - persistent, or $\neg P$ - not persistent), bioaccumulation potential ( $V B$ - very bioaccumulative, B - bioaccumulative, or $\neg B$ - not bioaccumulative), and LRTP. Percentages given in brackets refer to the respective numbers of substances, which resulted from the previous step. Dashed lines separate the number of substances which fail the respective following criterion by not more than 10\%, e.g. 5 of 104 substances which are $\neg$ P fail the P criterion by not more than $10 \%$. 
may contain SVHC, namely PBT compounds. This will be discussed in a later step.

\section{Screening for LRTP and comparison with potential Arctic contaminants}

When the LRTP screening methods are applied to the nine lists of sub-categories, in total 297 substances are identified as compounds with LRTP, which include the following:

(a) 4 compounds selected from the $8 \mathrm{vPvB}$ substances

(b) 3 selected from the $15 \mathrm{vPB}$ substances ( 1 from the 2 compounds which fail the $\mathrm{vB}$ criterion by less than $10 \%$ and 2 from the 13 compounds which fail the $\mathrm{vB}$ criterion by at least $10 \%$ or more)

(c) 125 detected from the $365 \mathrm{vP} \neg \mathrm{B}$ substances ( 2 from the 3 compounds which fail the $\mathrm{B}$ criterion by less than $10 \%$ and 123 from the 362 compounds which fail the B criterion by at least $10 \%$ or more)

(d)157 identified from the $525 \mathrm{P} \neg \mathrm{B}$ substances

(e) 9 from the $102 \neg \mathrm{P} \neg \mathrm{B}$ compounds

This can be further specified in regard of the single screening methods (Figure 2). For example, among the $v P v B$ substances (Figure 2a), all four compounds are detected to be prone to long-range transport by the half- life criterion in air $\left(t_{1 / 2 \text { (air) }}>2\right.$ days), two of them are also LRTP based on the modelling results with ELPOS and one compound is also identified to show LRTP according to Brown and Wania [8]. A similar picture can be observed for the $\mathrm{vPB}$ (Figure $2 \mathrm{~b}$ ), $\mathrm{vP} \neg \mathrm{B}$ (Figure $2 \mathrm{c}$ ) and $\mathrm{P} \neg \mathrm{B}$ (Figure $2 \mathrm{~d}$ ) substances, i.e. screening the compounds with the half-life criterion, which is a very rough approach, results in the largest set of organic substances with LRTP, whereas ELPOS delivers smaller sub-sets since this approach also considers the environmental distribution and fate of the respective chemicals based on a level-III fugacity assumption and is thus more restrictive. Some chemicals in the publicly available $\mathrm{REACH}$ database have been identified by Brown and Wania [8] to be potential Arctic contaminants. Only among the set of $\mathrm{vP} \neg \mathrm{B}$ compounds there are substances which are at the same time detected by all of the three screening approaches to be prone to LRT (ten chemicals), and one has even been published by Muir and Howard [9] to belong to the compounds with LRTP (Figure 2c). The nine substances which are LRTP but neither $\mathrm{P}$ nor $\mathrm{B}$ (case (e) in Figure 1) are not of interest as far as the identification of borderline chemicals is concerned. A complete overview of LRTP compounds from the $\mathrm{REACH}$ database (including classification according to $\mathrm{P}, \mathrm{B}$ and, if available, $\mathrm{T}$ ) is given in Additional file 1:

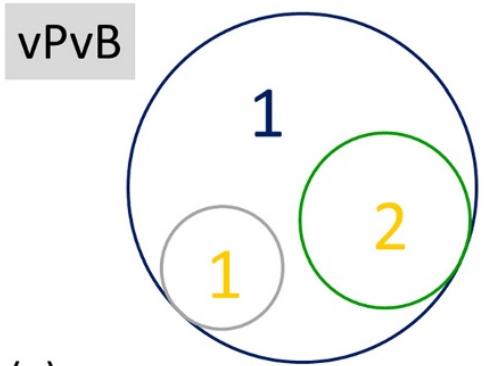

(a)

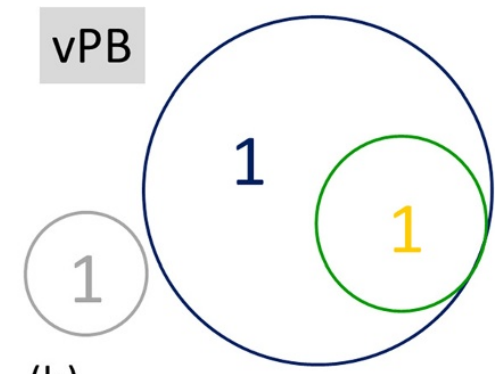

(b)

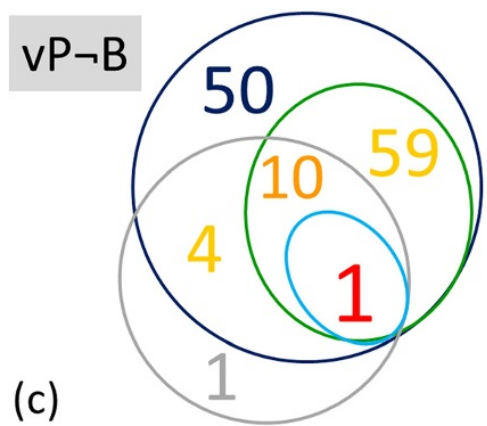

(d)

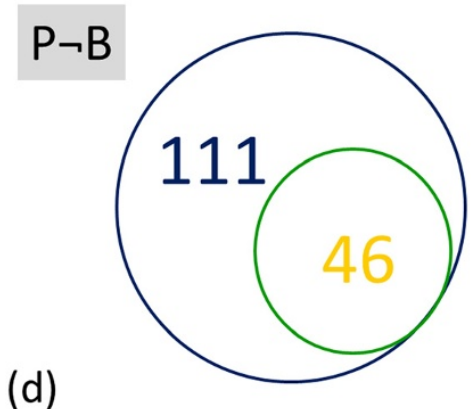

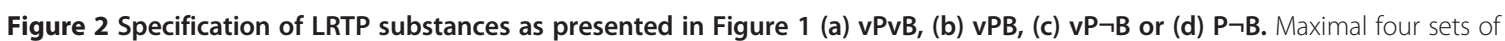
compounds are combined which are assumed to show LRTP derived from the half-life criterion ( $t_{1 / 2(\text { air })}>2$ days, dark blue circle), from simulations with the multimedia model ELPOS (green circle), from the chemical structure of known Arctic contaminants (grey circle) as given by Brown and Wania [8], and from the advanced half-life approach including a log $K_{\text {AW }}$ condition [9] ( $t_{1 / 2(a i r)}>2$ days and log $K_{\text {AW }} \geq 5$ and $\leq 1$, light blue circle; (c) only). 
Table S1. This table also reveals that, in addition to the eight SVHC substances which are vPvB (Figure 1), less than $2 \%$ of the organic, non-ionic substances in the publicly available REACH database are PBT. This fraction is lower than that identified by Zarfl et al. [10] on the Canadian Domestic Substance List (CDSL; $3.1 \%$ out of 5,091 compounds) and also smaller than the fraction of the findings of Strempel et al. [11] who detected 3\% of PBT chemicals by screening a set of approximately 95,000 compounds.

\section{Identification of potential borderline chemicals}

According to the definitions for borderline chemicals as given above, 13 borderline chemicals can be identified in total among the 1,022 organic, non-ionic compounds of the REACH database (Table 1). Thereof, one substance is vP, fails the REACH criterion ' $\mathrm{vB}$ ', but by less than $10 \%$ only, and shows LRTP. This compound is 1,2-dichloro4-(trichloromethyl)benzene. In the REACH database published in November 2011, 1-chloro-3-(4-chloropheno xy)-benzene (CAS 6842-62-2) could be characterized in the same way. Both substances have in common that their estimated partition coefficients $K_{\mathrm{OW}}$ and $K_{\mathrm{AW}}$ indicate strong sorption to organic material, i.e. a preliminary distribution into the soil compartment but also accumulation within organisms (estimated BCF of 1,2-dichloro-4-(trichloromethyl)benzene is 4,572 L $\mathrm{kg}^{-1}$ and that of 1-chloro-3-(4-chlorophenoxy)-benzene is 4,969 $\mathrm{L} \mathrm{kg}^{-1}$ ). Nevertheless, the half-life in air indicates LRTP for both compounds, whereas only 1,2dichloro-4-(trichloromethyl)benzene is also identified by the multimedia model ELPOS to show LRTP. The substance 1-chloro-3-(4-chlorophenoxy)-benzene has been removed from the pre-registration, which means that this compound is no longer allowed to be produced or to be placed on the market to more than 1 tonne in the European Union (EU). This indicates that 1,2-dichloro4-(trichloromethyl)benzene should be of the same concern. Experimental data from 2010 of the organic substance showed no biodegradation under test conditions [5] and thus confirm the persistence characterization. In addition, there are indications of genetic toxicity to Salmonella [12] and acute toxicity to Daphnia magna with a LOEC of $100 \mathrm{mg} \mathrm{L}^{-1}$ after $24 \mathrm{~h}$ [5]. However, the long-term toxicity test with a maximum of $100 \mathrm{mg} \mathrm{L}^{-1}$ did not show any adverse effects in comparison to the control [5]. According to Annex XIII of the $\mathrm{REACH}$ regulation, this means that 1,2-dichloro-4(trichloromethyl)benzene is not toxic and thus not PBT. In summary, this substance in the REACH database

Table 1 Thirteen substances in the publicly available REACH database 2012

\begin{tabular}{|c|c|c|c|c|c|c|c|c|c|c|c|}
\hline & \multirow[t]{2}{*}{ CAS } & \multirow[t]{2}{*}{ Name } & \multirow{2}{*}{$\begin{array}{l}\text { Log } \\
K_{\mathrm{OW}}\end{array}$} & \multirow{2}{*}{$\begin{array}{l}\log \\
K_{\mathrm{AW}}\end{array}$} & \multirow{2}{*}{$\begin{array}{c}\text { vPvB/PB } \\
\text { classification }\end{array}$} & \multicolumn{4}{|c|}{ LRTP according to } & \multirow{2}{*}{$\begin{array}{c}\mathrm{T} \\
\text { classification }\end{array}$} & \multirow[t]{2}{*}{ CDSL } \\
\hline & & & & & & $\begin{array}{l}t_{1 / 2(\text { air) }}> \\
2 \text { days }\end{array}$ & ELPOS & $\begin{array}{c}\text { Brown and } \\
\text { Wania [8] }\end{array}$ & $\begin{array}{l}\text { Muir and } \\
\text { Howard [9] }\end{array}$ & & \\
\hline (b) & $13014-24-9$ & $\begin{array}{l}\text { 1,2-Dichloro-4- } \\
\text { (trichloromethyl)benzene }\end{array}$ & 5.18 & -2.23 & $\checkmark P B$ & $x$ & $x$ & & & $\neg \top$ & \\
\hline \multirow[t]{2}{*}{ (c) } & $5216-25-1$ & a, $a, a, 4$-Tetrachlorotoluene & 4.54 & -2.10 & $v P \neg B$ & $x$ & $x$ & $x$ & & $\mathrm{~T}$ & \\
\hline & $2136-89-2$ & a, $a, a, 2$-Tetrachlorotoluene & 4.54 & -2.10 & $v P \neg B$ & $x$ & $x$ & & & $\mathrm{~T}$ & \\
\hline \multirow[t]{10}{*}{ (c) } & $87-61-6$ & 1,2,3-Trichlorobenzene & 3.93 & -1.01 & $\mathrm{vP} \neg \mathrm{B}$ & $x$ & $x$ & $x$ & & $\mathrm{~T}$ & $x$ \\
\hline & $120-82-1$ & 1,2,4-Trichlorobenzene & 3.93 & -1.01 & $\vee P \neg B$ & $x$ & $x$ & $x$ & & $\mathrm{~T}$ & $x$ \\
\hline & $102-36-3$ & $\begin{array}{l}\text { 3,4-Dichlorophenyl } \\
\text { isocyanate }\end{array}$ & 3.88 & -2.28 & $\vee P \neg B$ & $x$ & $x$ & $x$ & & $\mathrm{~T}$ & \\
\hline & $307-35-7$ & $\begin{array}{l}\text { Heptadecafluorooctane- } \\
\text { sulphonyl fluoride }\end{array}$ & 9.62 & 3.44 & $\vee P \neg B$ & $x$ & $x$ & $x$ & & $\mathrm{~T}$ & \\
\hline & $117-08-8$ & $\begin{array}{l}\text { 4,5,6,7-Tetrachloro-1,3- } \\
\text { isobenzofurandione }\end{array}$ & 4.65 & -4.10 & $\vee P \neg B$ & $x$ & $x$ & $x$ & $x$ & $\neg \top$ & $x$ \\
\hline & $108-77-0$ & 2,4,6-Trichloro-1,3,5-triazine & 1.73 & -4.66 & $\mathrm{vP} \neg \mathrm{B}$ & $x$ & $x$ & $x$ & & $\neg \top$ & $x$ \\
\hline & 2402-79-1 & 2,3,5,6-Tetrachloropyridine & 3.38 & -0.46 & $\mathrm{vP} \neg \mathrm{B}$ & $x$ & $x$ & $x$ & & $\neg \top$ & \\
\hline & $34893-92-0$ & $\begin{array}{l}\text { 1,3-Dichloro-5- } \\
\text { isocyanatobenzene }\end{array}$ & 3.88 & -2.28 & $v P \neg B$ & $x$ & $x$ & $x$ & & $\neg \top$ & \\
\hline & $98-56-6$ & $\begin{array}{l}\text { 4-Chloro-a,a,a- } \\
\text { trifluorotoluene }\end{array}$ & 3.6 & 0.15 & $\vee P \neg B$ & $x$ & $x$ & $x$ & & $?$ & \\
\hline & 29091-09-6 & $\begin{array}{l}\text { 2,4-Dichloro-1,3-dinitro-5- } \\
\text { (trifluoromethyl)benzene }\end{array}$ & 3.88 & -4.79 & $\vee P \neg B$ & $x$ & $x$ & $x$ & & $?$ & \\
\hline
\end{tabular}

The substances either are borderline chemicals (italics), for which one of the criteria for a SVHC is failed by not more than $10 \%$ but which are prone to long-range transport, or fulfil at least three of the screening criteria indicating LRTP (half-life criterion $t_{1 / 2(\text { air) }}>2$ days, multimedia model ELPOS, chemical profile of known Arctic contaminants according to Brown and Wania [8], or combination of the half-life criterion with the log $K_{\mathrm{AW}}$ condition defined by Muir and Howard [9], $\log K_{\mathrm{AW}} \geq 5$ and $\leq 1$ ) and fail one criterion to be accounted for a SVHC by more than $10 \%$ (extended borderline). 
represents case 1 of the borderline substances $\left(\mathrm{vP}_{\neg}(\mathrm{vB})\right)$ in the non-extended version, meaning that the indication of LRTP replaces the fact that $\mathrm{vB}$ is failed, but by less than $10 \%$ only.

The further 12 compounds given in Table 1 are also $\mathrm{vP}$ and fail vB. In contrast to the substances mentioned before, these compounds are not even $\mathrm{B}$, which indicates case 1 of the borderline substances but in the extended version (vB is failed by more than $10 \%$ ). Nevertheless, two compounds can be highlighted. This is $\alpha, \alpha, \alpha$, 4-tetrachlorotoluene which indicates LRTP by three of the screening methods, namely the half-life criterion, the multimedia model and results from Brown and Wania [8], and fails the $\mathrm{B}$ criterion by not more than $10 \%$. In addition, although there are only indications that $\alpha, \alpha, \alpha, 4$-tetrachlorotoluene has long-term effects on algae, experimental results show that this substance may cause cancer and damage fertility or the unborn child (reproductive toxicity) [5]. Thus, according to Annex XIII, it can be assumed to be toxic. This means that it belongs to the borderline substances of case 4, $\mathrm{P} \neg \mathrm{BT}$, and even in the non-extended version, since it fails the B criterion by less than $10 \%$ only, but shows LRTP according to three screening criteria.

The second compound to be highlighted is $\alpha, \alpha, \alpha$, 2-tetrachlorotoluene which also fails the $\mathrm{B}$ criterion by less than $10 \%$. Only two criteria, though, indicate LRTP, i.e. the half-life criterion and the simulation results with ELPOS. Since the substance is carcinogenic according to ECHA, it still belongs to case $4, \mathrm{P} \neg \mathrm{BT}$, of the borderline substances in the non-extended version.

The remaining ten substances belong, first of all, to the extended borderline substances of case $1, \mathrm{vP}_{\neg}(\mathrm{vB})$, in which vB (and even B) is failed and replaced by LRTP, but, in dependence of their toxicity, may also belong to case $4, \mathrm{P} \neg \mathrm{BT}$, in which $\mathrm{B}$ is failed and replaced by LRTP.

For example, both trichlorobenzenes (TCBs) belong to case 4 of the borderline chemicals since they are toxic according to the information of the CDSL. Their usage is as intermediates in the production process of pesticides and dyes and, formerly, also as dye carrier and corrosion inhibitor [13]. EPISuite is not able to differentiate between isomers such that estimated partition coefficients are equal (Table 1). Literature data collected for a European risk assessment of TCBs on half-lives in surface waters ( 2 to 3 days), sediments (>200 days) and soil (300 days) support the assumption that both compounds are vP [14]. Also, our result that TCBs are prone to LRT is supported by monitoring data in herrings of the North Sea and the Baltic Sea but especially in Arctic foxes [15]. This is confirmed by investigations presented in the EU Risk Assessment Report [14]. In addition, investigation results showed that the substances have longlasting very toxic effects on aquatic organisms $[5,16]$.
In the same way, 3,4-dichlorophenyl isocyanate and heptadecafluorooctane-sulphonyl fluoride belong to case 4 of the borderline substances in the REACH database. The first one shows acute toxicity to Daphnia magna with an $\mathrm{LC}_{50}$ of $0.23 \mathrm{mg} \mathrm{L}^{-1}$ [17] and is also 'very toxic to aquatic life with long lasting effects' [5]. The latter one can be classified as toxic due to its damage on reproductivity [5].

4,5,6,7-Tetrachloro-1,3-isobenzofurandione, in contrast, was identified by all investigated screening methods to be prone to LRT, but is not T. Thus, it belongs to the extended group of borderline substances which are $\mathrm{vP} \neg(\mathrm{vB})$, case 1 . However, there were no monitoring data available to support our screening results for LRTP. This may be due to the usage pattern of the compounds which is applied as an intermediate substance for dyes and medicines. Nevertheless, its usage as a flame retardant, e.g. in plastics and textiles, indicates environmental exposure.

The same case of borderline substances is true for 2,4,6-trichloro-1,3,5-triazine, 2,3,5,6-tetrachloropyridine and 1,3-dichloro-5-isocyanatobenzene. All of them are $\mathrm{vP}$, but not $\mathrm{vB}$ and not $\mathrm{T}$. No biodegradation was observed for these compounds. Although 1,3-dichloro-5isocyanatobenzene shows an acute toxicity on algae with an effect concentration (EC50) of $4.8 \mathrm{mg} \mathrm{L}^{-1}$ [18], indications for long-term toxicity are not sufficient to classify the compound as toxic according to REACH criteria defined in Annex XIII of the regulation.

Finally, for 4-chloro- $\alpha, \alpha, \alpha$-trifluorotoluene and 2,4dichloro-1,3-dinitro-5-(trifluoromethyl)benzene, data on long-term toxicity were not available. This means that both compounds belong not only to case $1(\mathrm{vP} \neg(\mathrm{vB}))$ of the borderline compounds, but also eventually to case 4 $(\mathrm{P} \neg \mathrm{BT})$. From the publicly available REACH database of November 2011, a substance (VERTREL (R) XF, CAS 34893-92-0) was removed which could be classified as $\mathrm{vP}, \neg \mathrm{B}$ and LRTP according to the three screening methods (half-life criterion, multimedia model, Arctic contaminant according to Brown and Wania [8]). The removal of this compound from pre-registration is at the same time an indication for concern for the borderline substances mentioned in Table 1.

\section{Sensitivity of borderline chemicals}

The sensitivity of the arbitrarily fixed '10\%' value for failing the criterion was the highest for the substances which are $\mathrm{vP}$ and fail the $\mathrm{vB}$ criterion (vPB substances, case (b) in Figure 1). Assuming that the $\mathrm{vB}$ criterion is failed by less than $5 \%$ (instead of 10\%) reveals that 1,2-dichloro-4-(trichloromethyl)benzene would not be considered as a borderline chemical anymore since its estimated BCF $\left(4,572 \mathrm{~L} \mathrm{~kg}^{-1}\right)$ falls below 4,750 $\mathrm{L} \mathrm{kg}^{-1}$ (=95\% of the criterion for $\mathrm{vB}, 5,000 \mathrm{~L} \mathrm{~kg}^{-1}$ ). This criterion is only fulfilled by retinol (CAS 68-26-8) which is, 
however, not prone to long-range transport and thus not a borderline substance neither. If the $\mathrm{vB}$ criterion may be failed by up to $15 \%$ instead, an additional substance (1-chloro-2-(chlorodiphenylmethyl)benzene, CAS 42074-68-0) has to be considered more closely. Since this compound shows no LRTP, however, it is not taken for a borderline substance.

The variability in the percentage leads to another change within the amount of substances which are vP but fail the $\mathrm{B}$ criterion $(\mathrm{vP} \neg \mathrm{B}$ substances, case (c) in Figure 1) when increasing the percentage from $10 \%$ to $15 \%$. In this case, an additional compound, 1,1,1,3, 3-pentachlorobutane (CAS 21981-33-9), would be included in the list of borderline chemicals. Its estimated BCF is larger than $1,700 \mathrm{~L} \mathrm{~kg}^{-1}$ (=85\% of the criterion for $\mathrm{B}, 2,000 \mathrm{~L} \mathrm{~kg}^{-1}$ ), and it is assumed to show LRTP by the half-life criterion in air and by ELPOS. Decreasing the percentage for failure from $10 \%$ to $5 \%$ does not change anything for the $\mathrm{vP} \neg \mathrm{B}$ substances. Furthermore, all other cases (vPvB, $\mathrm{PvB}, \mathrm{PB}, \mathrm{P} \neg \mathrm{B}, \neg \mathrm{PvB}, \neg \mathrm{PB}, \neg \mathrm{P} \neg \mathrm{B}$ ) are not sensitive to changes of the $10 \%$ value.

In summary, changing the arbitrarily set percentage for failure between $5 \%$ and $15 \%$ affects the list of borderline chemicals only slightly, i.e. assuming $5 \%$ of failure within the criteria produces a list of 12 compounds (without 1,2-dichloro-4-(trichloromethyl)benzene), assuming $10 \%$ leads to the list given in Table 1 and assuming $15 \%$ of possible failure results in a list of 14 substances including 1,1,1,3,3-pentachlorobutane.

\section{Conclusions}

First of all, the applied estimation methods bear uncertainties which may result in false positive or false negative compounds. False positive means, for example, that a compound is assumed to be a borderline chemical although, in reality, it is not. This example would be taken into closed consideration to be a SVHC, meaning that further investigations could clarify the actual characteristics. False negative, in contrast, includes, e.g. a compound which is excluded to be a borderline substance although it is one. This means that a possible substance of very high concern due to its LRTP and its short failure of only one of the $\mathrm{VPvB}$ and PBT criteria is not identified by the screening procedure. This is, of course, the case which should be excluded. Therefore, we propose to combine different methods, i.e. half-life criteria, multimedia modelling and monitoring data, to identify borderline chemicals as potential high-priority chemicals for further analysis to reduce the uncertainty resulting from each of the classification methods.

The definition of borderline chemicals and the directly implemented screening approach help to prioritize potential substances of very high concern or of equivalent concern out of a long list of chemicals. This is of special importance with regard to registration and evaluation tasks in the European Union of all substances in production and use. Nevertheless, the definition of the criteria indicating borderline chemicals has to be further discussed. Cases (a) and (b) refer to the substances that fail to be $\mathrm{vPvB}$, i.e. either the $\mathrm{vP}$ or the $\mathrm{vB}$ criterion is not fulfilled. If the substance shows LRTP instead, then it is regarded to be a borderline chemical and of equivalent high concern. This is a strong condition but goes along with the idea that $\mathrm{vPvB}$ can replace $\mathrm{PBT}$, meaning that a substance which is not toxic is still of very high concern as soon as its persistence and bioaccumulation potential are very high. Since toxicity is hard to be predicted under different environmental conditions and for especially sensitive organisms in remote regions, the precautionary principle asks for dealing carefully with $\mathrm{vPvB}$ substances [19]. The reason is that even if the toxicity criterion is not fulfilled, the respective compound may show toxic effects under extreme conditions. The same holds for compounds which are vP and show LRTP since remote regions will be exposed to the substance (due to LRTP) for a very long time (due to its strong persistence). Similarly, compounds which are vB and show LRTP may reach remote regions (due to LRTP) and will strongly accumulate in the organisms there (due to their high bioaccumulation potential).

Cases (c) to (e) indicate that although one of the P, B and $\mathrm{T}$ criteria is failed, the substance is still of very high concern as soon as it is characterized by LRTP. The argument is similar to the one above: Long-range transport potential, in combination with at least two of the characteristics $\mathrm{P}, \mathrm{B}$ or $\mathrm{T}$, turns a substance into a potential hazard to remote regions [2]. Since we defined that LRTP has to be shown by at least three of the indicators to keep uncertainties as small as possible, these cases have not occurred among the compounds of the REACH database. In contrast, all identified borderline chemicals are $\mathrm{vP}$ and, except one, not $\mathrm{B}$.

Finally, the borderline approach highlights, first of all, three substances in the REACH database which might be SVHC although they do not fulfil the criteria defined under $\mathrm{REACH}$. For these, a subsequent experimental analysis and monitoring data are, of course, necessary to support or reject the assumption of the estimated substance properties used for the screening approach. Expanding the borderline conditions still ends up in a list of ten additional compounds with strong indications to be SVHCs. This means that in this way, there is a two-step approach to systematically identify borderline chemicals under REACH which might - if neglected - pose an undiscovered hazard to our environment. Other approaches to determine P (e.g. applying the soil criterion only [11]) or B (BAF instead of BCF) can replace the methods integrated in our investigation and may give further hints on critical substance candidates. 


\section{Methods}

\section{Outline}

For the identification of potential borderline chemicals, the following procedure was applied to the publicly available REACH database of June 2012. This procedure is similar to the one described in Zarfl et al. [10] for the identification of possible substances of very high concern from the CDSL [20]. However, due to the focus on borderline chemicals under REACH, another order of the single screening steps was applied. Moreover, the REACH database contains less information than the CDSL.

The REACH database includes information on the EC number, the CAS number and the substance name as well as information on the registration status, i.e. if the substance is registered as a full dossier (3,537 substances out of 5,306 ) or as an isolated intermediate (on-site isolated or transported isolated intermediate; 2,510 substances are respective intermediates, thereof 744 compounds are registered as a full dossier). In contrast to the CDSL, which contains all substances in use on the Canadian market, the REACH database does not include information on the chemical's type (organic, inorganic, etc.) and toxicity (toxic or not toxic). Therefore, we first check which of the compounds in the REACH database are already contained in the CDSL such that more information on the respective compounds is already available.

First, all organic substances are classified according to their environmental fate defined by REACH criteria, i.e. persistence (P) and bioaccumulation potential (B), as well as LRTP. The underlying screening methodology is based on substance properties estimated by quantitative structure-activity relationships (QSAR). The property estimation methods are implemented in the EPISuite software package [6], an estimation tool published by the Environmental Protection Agency of the USA. Here it is assumed that all molecules for which properties are to be estimated are available in their non-ionic state. Therefore, our screening procedure is reduced to compounds which mainly appear in their neutral form within the environmentally relevant $\mathrm{pH}$ range.

Our screening criteria used for LRTP are based on two different concepts: On the one hand, we refer to the definition of the Stockholm Convention which states that a substance will 'migrate [] significantly through the air' [3] if its atmospheric oxidation half-life exceeds 2 days. This criterion alone, however, does not consider the environmental distribution and degradation behaviour in various compartments. In Annex D of the Stockholm Convention, it is thus complemented by additional conditions with regard to 'environmental fate properties and/or model results that demonstrate that the chemical has a potential for long-range environmental transport'. Therefore, we also consider the well-acknowledged concept of the characteristic travel distance (CTD) as a screening criterion for the identification of compounds with LRTP which is investigated in parallel to the half-life criterion. The CTD is calculated by the multimedia model ELPOS [21]. This approach is based on the assumption that compounds which show a similar CTD to the CTD of acknowledged reference chemicals for POP-like behaviour should also be considered as substances that might have LRTP [22]. In addition, each substance is crosschecked for LRTP with the available list of 120 organic high-production-volume chemicals (HPVCs) identified by Brown and Wania [8] and a list of top 28 persistent and bioaccumulative substances identified by Muir and Howard [9] which all indicate to be transported to remote regions.

Finally, based on the estimated substance properties and in combination with the defined criteria for persistence, bioaccumulation potential and LRTP, SVHC and borderline chemicals are identified within the organic non-ionic compounds of the REACH database.

\section{Screening for non-ionic compounds}

The publicly available REACH database was, in a first step, searched for organic compounds which are nonionic to at least $95 \%$ in the environmentally relevant $\mathrm{pH}$ range of 4 to 10 . This percentage was arbitrarily chosen close to $100 \%$ to minimize subsequent errors in the property calculation with EPISuite, which assumes all molecules to be available in their neutral state. To identify the organic substances in the REACH database, all compounds which are also contained in the CDSL can be checked for the chemical's type easily since this information is contained in the CDSL. Those compounds, which are not contained in the CDSL but in the REACH database only, are investigated one by one based on the chemical's name and molecular structure if they are organic substances or not. In this way, only the organic compounds are chosen for further analysis. Next, the whole list of organic substances was investigated with the SPARC On-line Calculator v4.5 to identify the acid dissociation constants $p K_{\mathrm{a}}$, which are estimated from the molecular structure based on QSAR. SPARC has already been evaluated in earlier literature for more than 4,300 dissociating species [23]. SPARC also delivers the fraction of each of the ionic and non-ionic species for several $\mathrm{pH}$ values. This means that only substances for further screening were chosen if the non-ionic fractions at $\mathrm{pH} 4$ and 10 amount to $95 \%$ or more. This condition is sufficient to ensure that the non-ionic fraction does not drop below $95 \%$ within the whole range from $\mathrm{pH} 4$ to 10 since the graph of the species fraction in dependence of the $\mathrm{pH}$ value is convex in the nearest neighbourhood of the global maximal value (Figure 3). 


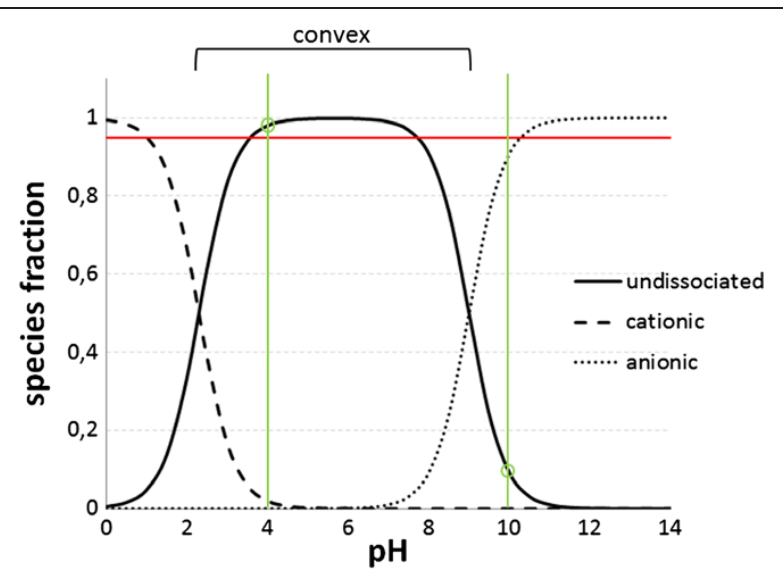

Figure 3 Species distribution of a dissociating substance with two $p K_{\mathrm{a}}$ values (2.5 and 9) in dependence of $\mathrm{pH}$. For property estimations with EPISuite, the non-ionic fraction is of importance which was set to be at least 95\% (red line) within an environmental relevant $\mathrm{pH}$ range of 4 to 10 (green lines). This example substance would not be included for further screening steps since the nonionic species drops far below $95 \%$ at $\mathrm{pH} 10$. The respective graph is convex within the range of interest.

\section{Estimation of substance properties}

After having identified all organic non-ionic compounds in the $\mathrm{REACH}$ database, these substances are run through the batch mode of the software package EPISuite v4.10 to quantify physical-chemical substance properties by the implemented estimation methods. The program input for EPISuite is a list of SMILES codes of the organic non-ionic substances deduced from the CAS numbers, which are given in the REACH database. The parameters obtained from the estimation with EPISuite and needed for the further screening methods are the CAS number and substance name for identification; molecular mass $\left(\mathrm{g} \mathrm{mol}^{-1}\right)$; logarithmic octanol-water partition coefficient $\log K_{\mathrm{OW}}$; air-water partition coefficient $K_{\mathrm{AW}}$; degradation half-lives $\left(t_{1 / 2}\right)$ in air, water, sediment and soil (in days); and BCF according to the ArnotGobas method [24]. For some of the compounds, the database of EPISuite also contains experimental values determined for chemical properties. However, for comparability and reproducibility reasons, we only consider calculated values in this early screening step. A refined investigation of substance properties is included in a last step to analyse the reliability of the screening method.

\section{Screening for persistence, bioaccumulation potential and toxicity}

The estimated parameter values are used to classify compounds according to their environmental fate with focus on persistence (P), bioaccumulation potential (B) and LRTP to identify SVHC and borderline chemicals which are contained in the $\mathrm{REACH}$ database. For a refined analysis, toxicity information (toxic or not toxic) is included.

Since REACH defines that SVHCs are either vPvB or PBT, the threshold values for $\mathrm{vP}, \mathrm{P}, \mathrm{vB}$ and $B$ were chosen according to Annex XIII of the European regulation as mentioned above in the 'Background' section.

With these criteria only, nine sub-categories of vP, P, $\mathrm{vB}$ and $\mathrm{B}$ combinations can be defined, which are the following (' $\neg$ ' is the logical symbol for 'not'):

1. $\mathrm{vPvB}$ (very persistent, very bioaccumulative)

2. $\mathrm{vPB}$ (very persistent, bioaccumulative)

3. $v P \neg B$ (very persistent, not bioaccumulative)

4. $\mathrm{PvB}$ (persistent, very bioaccumulative)

5. PB (persistent, bioaccumulative)

6. $\mathrm{P} \neg \mathrm{B}$ (persistent, not bioaccumulative)

7. $\neg \mathrm{PvB}$ (not persistent, very bioaccumulative)

8. $\neg \mathrm{PB}$ (not persistent, bioaccumulative)

9. $\neg \mathrm{P} \neg \mathrm{B}$ (not persistent, not bioaccumulative)

In addition, all those substances are identified, which miss one of the criteria by up to $10 \%$ or in other words fulfil one of the criteria to more than $90 \%$ but less than $100 \%$. This means that those compounds which miss the vP criterion by up to $10 \%$ are a sub-group of the substances which are P, i.e. half-life of degradation in fresh water $>54$ days but $\leq 60$ days or in sediment $>162$ days but $\leq 180$ days or in soil $>162$ days but $\leq 180$ days. Consequently, those compounds which miss the P criterion by up to $10 \%$ are a sub-group of the substances which are $\neg$ P, i.e. half-life of degradation in fresh water $>36$ days but $\leq 40$ days or in sediment $>108$ days but $\leq 120$ days or in soil $>108$ days but $\leq 120$ days. The same approach is applied for the bioaccumulation potential, i.e. those compounds which miss the $\mathrm{vB}$ criterion by up to $10 \%$ are a sub-group of the substances which are B (BCF $>4,500 \mathrm{~L} \mathrm{~kg}^{-1}$ but $\leq 5,000 \mathrm{~L} \mathrm{~kg}^{-1}$ ), and those compounds which miss the $\mathrm{B}$ criterion by up to $10 \%$ are a sub-group of the substances which are $\neg \mathrm{B}$ $\left(\right.$ BCF $>1,800 \mathrm{~L} \mathrm{~kg}^{-1}$ but $\leq 2,000 \mathrm{~L} \mathrm{~kg}^{-1}$ ).

Toxicity information is either given in the CDSL (toxic or not toxic) for all compounds contained in both the publicly available REACH database and the CDSL or, if necessary, has to be investigated in more detail via a literature research. Literature data are then compared to criteria for toxicity defined in Annex XIII of the REACH regulation, i.e. a substance is $\mathrm{T}$ if (1) the long-term no observed effect concentration is smaller than $0.01 \mathrm{mg} \mathrm{L}^{-1}$; (2) the substance is carcinogenic, mutagenic or toxic to reproduction; or (3) there is other evidence for longterm toxicity. 


\section{Screening for LRTP and comparison with potential Arctic contaminants}

In a next step, each of the nine sub-lists is edited in two ways to identify compounds with LRTP. On the one hand, for all organic and mostly (>95\%) non-ionic compounds, the half-life criterion for long-range transport in air as defined in the Stockholm Convention was applied ( $t_{1 / 2(\text { air) }}$ exceeding 2 days). On the other hand, the same substances were simulated with the multimedia model ELPOS. ELPOS is a simplified version of the regional-scale model EUSES-SimpleBox which is applied for chemical assessment in the European Union [25]. Within the model, the environmental compartments air, freshwater, sediment and three different kinds of soil, namely natural, agricultural and rural/urban soil, are taken into account. It represents a level-III fugacity model assuming steady state but accounting for the emission compartment. In addition, transfer processes between different compartments and advective outflow of the substance out of the model system are considered. More details on the model formulation and parameters are given by Beyer and Matthies [26].

ELPOS calculates the CTD as an indicator for LRTP [27]. It is a relative metric for the transport distance (in $\mathrm{km}$ ) that an organic chemical travels in air or water until about $37 \%(1 / e)$ of the initial concentration remains. Whereas the persistence criterion already covers LRTP in water by referring to the half-life in water [4], the CTD goes beyond that approach. More details concerning CTD are given by Beyer et al. [28]. The respective values of these metrics resulting from simulations with ELPOS are compared with the implemented and well-established set of reference chemicals for POP-like behaviour and non-POP-like behaviour. According to the boundaries derived from these reference chemicals and defined for LRTP and persistence by Klasmeier et al. [22], four substance categories can be differentiated:
A: High persistence, high LRTP (POP-like)
B: Low persistence, high LRTP
C: High persistence, low LRTP
D: Low persistence, low LRTP (non-POP-like)

So categories A and B represent the group of compounds which are characterized by LRTP. Categories C and, especially, D are of minor importance since included compounds will not be of very high concern in terms of LRTP.

Muir and Howard [9] investigated the CDSL and hypothesised that 28 persistent and bioaccumulative substances of the substance list can be regarded as the top compounds, which show LRTP according to the Stockholm Convention, i.e. the half-life criterion $t_{1 / 2 \text { (air) }}$
$>2$ days, and according to the distribution coefficient between air and water $\left(K_{\mathrm{AW}}\right)$ restricting LRTP to compounds characterized by $\log K_{\mathrm{AW}} \geq 5$, i.e. mainly distributed into the air compartment, and $\leq 1$, i.e. mainly distributed into water [29]. Brown and Wania [8] published a list of 120 HPVCs which match the structure of known Arctic contaminants or had been identified as potential Arctic contaminants by a modelling approach. We thus compare these two substance lists with the results of our multimedia model-based methodology not only to identify limits of our screening approach, but also to suggest a first prioritization for further research as far as possible SVHCs are concerned.

\section{Identification of potential borderline chemicals}

Substances that fail one of the criteria (vP or $\mathrm{vB}, \mathrm{P}$ or B or $\mathrm{T}$ ), which have to be fulfilled in order to be identified as a SVHC according to REACH and are, at the same time, identified to show high LRTP according to at least one of the LRTP screening methods, are defined as potential borderline cases. We differentiate them as follows:

1. Substances which fail one of the REACH criteria by not more than $10 \%$ but show LRTP

2. Substances which fail one of the criteria by more than $10 \%$ and which fulfil at least three of the screening criteria indicating LRTP (half-life criterion $t_{1 / 2 \text { (air) }}>2$ days, multimedia model ELPOS, chemical profile of known Arctic contaminants according to Brown and Wania [8], or combination of the halflife criterion with the $\log K_{\mathrm{AW}}$ condition defined by Muir and Howard [9], $\log K_{\mathrm{AW}} \geq 5$ and $\leq 1$ ) (extended borderline chemicals)

This includes the following five cases:
(a) $v P \neg(v B)+$ LRTP (vB is failed and replaced by LRTP)
(b) $\neg(v P) v B+$ LRTP (vP is failed and replaced by LRTP)
(c) $\mathrm{PB} \neg \mathrm{T}+\mathrm{LRTP}$ ( $\mathrm{T}$ is failed and replaced by LRTP)
(d) $\neg \neg B T+$ LRTP (B is failed and replaced by LRTP)
(e) $\neg$ PBT + LRTP (P is failed and replaced by LRTP)

The meaning of these cases for the substances on the publicly available REACH database is investigated ((c) and (d) are sub-cases of (a), but (a) includes also PBT and $\mathrm{P} \neg \mathrm{B} \neg \mathrm{T})$ and discussed also by an additional literature research with regard to environmental fate and toxicity. In addition, a sensitivity analysis is conducted varying the percentage of by how much the criteria are failed between $85 \%$ and $95 \%$. 


\section{Additional file}

Additional file 1: Supporting information. The file contains the complete list of substances with LRTP from the REACH database (Table S1) and results for replacing BCF by BAF as an indicator for B (Table S2).

\section{Abbreviations}

B: Bioaccumulative; BAF: Bioaccumulation factor; BCF: Bioconcentration factor; CDSL: Canadian Domestic Substance List; CTD: characteristic travel distance; ECHA: European Chemicals Agency; LRTP: Long-range transport potential; P: Persistent; POP: Persistent organic pollutant; REACH: Registration Evaluation, Authorization and Restriction of Chemicals; SVHC: Substances of very high concern; T: Toxic; vB: Very bioaccumulative; vP: Very persistent.

\section{Competing interests}

The authors declare that they have no competing interests.

\section{Authors' contributions}

CZ and MM contributed equally to the ideas and writing of the paper. CZ carried out the screening procedure and literature research and drafted the manuscript. Both authors read and approved the final manuscript.

\section{Acknowledgements}

We thank our colleagues Ines Hotopp and Nils Kehrein, Institute of Environmental Systems Research Osnabrück, for the simulations with SPARC and ELPOS, and the German Federal Environmental Agency for the financial support.

Received: 27 January 2013 Accepted: 16 April 2013

Published: 4 May 2013

\section{References}

1. European Commission: Regulation (EC) No 1907/2006 of the European Parliament and of the Council of 18 December 2006 concerning the Registration, Evaluation, Authorisation and Restriction of Chemicals (REACH). [http://eur-lex.europa.eu/JOHtml.do?uri=OJ:L:2006:396:SOM:EN:HTML].

2. ECHA: Guidance on information requirements and chemical safety assessment. Chapter R.11: PBT assessment. [http://echa.europa.eu/reach_en.asp]

3. UNEP: Stockholm Convention on Persistent Organic Pollutants. [http://chm. pops.int/Convention/ConventionText/tabid/2232/ Default.aspx].

4. Zarfl C, Scheringer M, Matthies M: Screening criteria for long-range transport potential of organic substances in water. Environ Sci Technol 2011, 45:10075-10081

5. European Chemicals Agency Helsinki: Information on chemicals. Registered substances. [http://echa.europa.eu/information-on-chemicals/registeredsubstances].

6. US EPA: Estimation Programs Interface Suite ${ }^{\mathrm{TM}}$ for Microsoft ${ }^{\oplus}$ Windows, v 4.10 . Washington, DC; 2012

7. McLachlan MS, Czub G, MacLeod M, Arnot JA: Bioaccumulation of organic contaminants in humans: a multimedia perspective and the importance of biotransformation. Environ Sci Technol 2011, 45:197-202.

8. Brown T, Wania F: Screening chemicals for the potential to be persistent organic pollutants: a case study of Arctic contaminants. Environ Sci Technol 2008, 42:5202-5209.

9. Muir DCG, Howard PH: Are there other persistent organic pollutants? A challenge for environmental chemists. Environ Sci Technol 2006, 40:7157-7166.

10. Zarfl C, Hotopp I, Kehrein N, Matthies M: Identification of substances with potential for long-range transport as possible substances of very high concern. Environ Sci Pollut Res 2012, 19:3152-3161.

11. Strempel S, Scheringer M, Ng C, Hungerbühler K: Screening for PBT chemicals among the "existing" and "new" chemicals of the EU. Environ Sci Technol 2012, 46:5680-5687.

12. Zeiger E, Anderson B, Haworth S, Lawlor T, Mortelmans K: Salmonella mutagenicity tests. V. Results from the testing of 311 chemicals. Environ Mol Mutagen 1992, 19:2-141.

13. Caux PY, Kent RA, Fan GT, Stephenson GL: Environmental fate and effects of chlorothalonil: a Canadian perspective. Critical Reviews in Environ Sci Technol 1996, 26:45-93.
14. Hansen BG, Munn SJ, Luotamo M, Musset C, Pakalin S, de Bruijn J, Berthault F, Vegro S, Pellegrini G, Allanou R, Scheer S: European Union Risk Assessment Report: 1,2,4-trichlorobenzene, vol. 26. [http://echa.europa.eu/documents/ 10162/44180838-c246-4d42-9732-45e2af411e52].

15. Strachan WMJ, Burniston DA, Williamson M, Bohdanowicz H: Spatial differences in persistent organochlorine pollutant concentrations between the Bering and Chukchi Seas (1993). Mar Pollut Bull 2001, 43:132-142

16. Galassi S, Vighi M: Testing toxicity of volatile substances with algae. Chemosphere 1981, 10:1123-1126.

17. Adema DMM, Vink GJ: A comparative study of the toxicity of 1,1,2trichloroethane, dieldrin, pentachlorophenol and 3,4-dichloroaniline for marine and fresh water organisms. Chemosphere 1981, 10:533-554.

18. Adema DMM, Kuiper J, Hanstveit AO, Canton HH: Consecutive system of tests for assessment of the effects of chemical agents in the aquatic environment. Pestic Chem 1981, 3:537-544.

19. Scheringer M: Persistence and Spatial Range of Environmental Chemicals: New Ethical and Scientific Concepts for Risk Assessment. 1st edition. Weinheim: Wiley-VCH; 2009

20. Environment Canada: Acts \& Regulations. Domestic Substances List. [www.ec gc.ca/lcpe-cepa/default.asp?lang=En\&n=5F213FA8-1]

21. Institute of Environmental Systems Research Osnabrück (USF): ELPOS 2.2. Environmental Long-Range Transport and Persistence of Organic Substances. [www.usf.uos.de/usf/arbeitsgruppen/ASW/ELPOS.en.html]

22. Klasmeier J, Matthies M, MacLeod M, Fenner K, Scheringer M, Stroebe M, Le Gall AC, McKone T, van de Meent D, Wania F: Application of multimedia models for screening assessment of long-range transport potential and overall persistence. Environ Sci Technol 2006, 40:53-60.

23. Hilal SH, Karickhoff SW: A rigorous test for SPARC's chemical reactivity models: estimation of more than 4300 ionization $\mathrm{pK}_{\mathrm{a}} \mathrm{s}$. Quant Struct - Act Relat 1995, 14:348-355.

24. Arnot JA, Gobas FAPC: A generic QSAR for assessing the bioaccumulation potential of organic chemicals in aquatic food webs. QSAR Comb Sci 2003, 22:337-345.

25. European Commission: EUSES 21.2. The European Union System for the Evaluation of Substances. [http://ihcp.jrc.ec.europa.eu/our_activities/publichealth/risk_assessment of Biocides/euses]

26. Beyer A, Matthies M: Criteria for Atmospheric Long-Range Transport and Persistence of Pesticides and Industrial Chemicals. Berlin: E. Schmidt Verlag; 2002.

27. Matthies M, Klasmeier J, Beyer A, Ehling C: Assessing persistence and longrange transport potential of current-use pesticides. Environ Sci Technol 2009, 43:9223-9229.

28. Beyer A, Mackay D, Matthies M, Wania F, Webster E: Assessing long-range transport potential of persistent organic pollutants. Environ Sci Technol 2002, 34:699-703.

29. Fenner K, Scheringer M, Macleod M, Matthies M, McKone T, Stroebe M, Beyer A, Bonnell M, Le Gall AC, Klasmeier J, Mackay D, van de Meent D, Pennington D, Scharenberg B, Suzuki N, Wania F: Comparing estimates of persistence and long-range transport potential among multimedia models. Environ Sci Technol 2005, 39:1932-1942.

doi:10.1186/2190-4715-25-11

Cite this article as: Zarfl and Matthies: PBT borderline chemicals under REACH. Environmental Sciences Europe 2013 25:11.

\section{Submit your manuscript to a SpringerOpen ${ }^{\circ}$ journal and benefit from:}

- Convenient online submission

- Rigorous peer review

- Immediate publication on acceptance

- Open access: articles freely available online

- High visibility within the field

- Retaining the copyright to your article

Submit your next manuscript at springeropen.com 